\title{
Modulation of ACTH-induced cortisol release by polyunsaturated fatty acids in interrenal cells from gilthead seabream, Sparus aurata
}

\author{
R Ganga, L Tort ${ }^{1}$, L Acerete ${ }^{1}$, D Montero and M S Izquierdo \\ Grupo de Investigación en Acuicultura, Instituto Canario de Ciencias Marinas, PO Box 56, 35200-Telde, Las Palmas, Canary Islands, Spain \\ ${ }^{1}$ Department of Cell Biology, Physiology and Immunology, Universitat Autonòma de Barcelona, Bellaterra 08193, Spain \\ (Requests for offprints should be addressed to R Ganga; Email: rgaqua2003@yahoo.fr)
}

\begin{abstract}
Highly unsaturated fatty acids are essential components of cellular membranes of vertebrates and can modulate physiological processes, including membrane transport, receptor function and enzymatic activities. In gilthead sea bream, dietary deficiencies of essential fatty acids of marine fish raise the basal cortisol levels and alter the pattern of cortisol release after stress. The aim of the present study was to clarify the effect of different essential fatty acids on adrenocorticotropic hormone (ACTH)-induced cortisol production and release in fish, through in vitro studies of sea bream interrenal cells maintained in superfusion and incubated with different types of fatty acids and eicosanoid production inhibitors. Results showed the first evidence of the effect of certain fatty acids on cortisol production by
\end{abstract}

ACTH-stimulated interrenal cells in fish. Both arachidonic acid (ARA) and particularly eicosapentaenoic acid (EPA) promoted cortisol production in sea bream interrenal cells. Moreover, incubation with indometacin (INDO) reduced the increased cortisol production induced by EPA and ARA, suggesting mediation by their cyclooxygenase-derived products. Docosahexaenoic acid stimulated cortisol production to a lesser extent than that caused by EPA or ARA, but the inhibitory effect of INDO was not as marked as it was for the other fatty acids. In contrast, supplementation with dihomogammalinoleic acid reduced cortisol production, denoting the inhibitor effect of this fatty acid in cortisol secretion.

Journal of Endocrinology (2006) 190, 39-45

\section{Introduction}

Highly unsaturated fatty acids with 20 or more carbon atoms and three or more double bonds (HUFA) are essential components of cellular membranes and can modulate physiological processes, including membrane transport, receptor function and enzymatic activities. Hence, dietary fatty acids have been shown to have marked effects on a variety of immunological and haemostatic parameters (Balfry et al. 2001, Montero et al. 2001). HUFA possess a wide range of cellular functions. One of the most important functions is to supply precursors for the synthesis of eicosanoids, which are produced in response to various extracellular stimuli by two main types of dioxygenase enzymes: cyclooxygenases (COX) and lipoxygenases (Horrobin 1983). Following cell stimulation, both arachidonic acid (ARA; 20:4n-6) and eicosapentaenoic acid (EPA; 20:5n-3) are released from the membrane by the action of phospholipase $A_{2}$. Later these fatty acids are transformed by a range of lipoxygenases and cyclooxygenases to yield prostaglandins $(\mathrm{PG})$, leukotrienes, lipoxins and other compounds, which can modulate several immune functions (Uhing et al. 1990).

Eicosanoids have been found in a large range of freshwater and marine fish (Matsumoto et al. 1989, Mustafa \& Srivastava
1989) and in many tissues (Henderson \& Tocher 1987, Bell et al. 1994a, Tocher 1995). In fish, a preferred eicosanoid precursor for cyclooxygenase seems to be ARA (20:4n-6) (Tocher \& Sargent 1987, Bell et al. 1994a, 1994b, 1998), but EPA (20:5n-3) and dihomo- $\gamma$-linolenic acid (DHGLA; 20:3n-6) are also important eicosanoid precursors which can modulate production and biological efficacy of ARAderived eicosanoids (Horrobin 1983, Bell et al. 1994a, Ganga et al. 2005). In addition, the high content of docosahexaenoic acid (DHA; 22:6n-3) in cellular membranes affects eicosanoid production (Nablone et al. 1990). This fatty acid is also recognised as a precursor of certain biologically active trioxilated derivatives (German et al. 1983, Hong et al. 2005). Therefore, the supply of precursor polyunsaturated fatty acids with 18 or more carbon atoms and two or more double bonds (PUFA) for eicosanoid synthesis is directly related to the fatty acid composition of membrane phospholipids, which in turn is influenced by dietary PUFA intake and metabolism (Lands 1989).

In gilthead sea bream, dietary deficiencies on n-3 HUFA, essential fatty acids for marine fish (Izquierdo 1996), raised the basal plasma cortisol levels and altered the pattern of cortisol release after stress (Montero et al. 1998). Cortisol is a key corticosteroid hormone for homeostatic response to stress 
in all vertebrates, through its effects on metabolism and immune function (Hontela 1997, Wendelaar Bonga 1997) as well as the osmoregulation process (Wendelaar Bonga 1997). Thus, the increase in plasma cortisol levels is regarded as the most reliable method for differentiating between stressed and non-stressed fish (Thompson et al. 1993, Yin et al. 1995, Rotllant \& Tort 1997). Moreover, feeding relatively low levels of n-3 HUFA, although not affecting growth and feed efficiency, significantly raised plasma cortisol levels (Montero et al. 2003).

However, the physiological mechanisms by which these HUFA regulate the hormone-induced plasma cortisol levels are not clear. In fish, several studies have suggested that ARA is involved in the release of cortisol, although the actual mechanisms have not been investigated (Gupta et al. 1985, Bessonart et al. 1999, Harel et al. 2001, Koven et al. 2003, Van Anholt et al. 2004). In mammals, certain studies suggest that PG play an important role in mediating the corticosteroidogenic action of adrenocorticotropic hormone (ACTH) (Kocsis et al. 1999), and thus the role of fatty acids in stress response seems to be mediated by the production of eicosanoids.

The present study aims to clarify the effect of different HUFA on ACTH-induced cortisol production and release by gilthead sea bream interrenal cells.

\section{Material and Methods}

\section{Animals}

Sexually immature gilthead sea bream (Sparus aurata) of body weight $54 \cdot 7 \pm 11 \cdot 2 \mathrm{~g}$ supplied by a Spanish fish farm (Masnou, Barcelona, Spain) were kept for 2 weeks in two fibreglass tanks of 10001 held in a semi-closed seawater circulation system equipped with physical and biological filters. Water temperature was maintained at $16-18{ }^{\circ} \mathrm{C}$, the salinity at $35-40 \%$ and photoperiod at $12 \mathrm{~h}$ light: $12 \mathrm{~h}$ darkness. Fish were fed once a day with a commercial feed until $24 \mathrm{~h}$ before the in vitro trials to avoid feed interference. A total number of 30 fish were employed in the experiments.

\section{Superfusion trials}

After 2 weeks of acclimatisation, fish were randomly taken from the tanks in less than $1 \mathrm{~min}$, immediately anaesthetised with 2-phenoxyethanol $(1: 1000 \mathrm{v} / \mathrm{v})$ and blood collected with a hypodermic syringe from the caudal vein to minimise the haemorrhage. Head kidney tissue was removed from two fish in each superfusion trial and cut into very small fragments in Hepes Ringer medium, which was used as the superfusion medium. Afterwards, head kidney homogenates were pooled and distributed in eight superfusion chambers (volume: $0.2 \mathrm{ml}$ ) in order to obtain a homogeneous aliquot from each of them. Tissues were superfused with a Hepes $(\mathrm{pH} 7 \cdot 4)$ Ringer's solution containing $171 \mathrm{mM} \mathrm{NaCl}, 2 \mathrm{mM} \mathrm{KCl}$, $2 \mathrm{mM} \mathrm{CaCl}{ }_{2} \mathrm{H}_{2} \mathrm{O}, 0 \cdot 25 \%(\mathrm{w} / \mathrm{v})$ glucose and $0 \cdot 03 \%(\mathrm{w} / \mathrm{v})$ bovine serum albumin (Rotllant et al. 2001). The system was temperature-controlled at $15^{\circ} \mathrm{C}$ and superfusion medium was pumped through the chamber at a rate of $75 \mu \mathrm{l} / \mathrm{min}$ by a Masterplex L/S ${ }^{\mathrm{R}}$ multichannel peristaltic pump (Cole Parmer Instrument Co. Vernon Hills, IL, USA).

Trials were started after $3 \mathrm{~h}$ of superfusion when cortisol reached a stable baseline level (Rotllant et al. 2000a, 2000b) due to several factors such as the different dispersion of interrenal cells in the perfusion preparation, individual differences and the pre-stress level of each fish. After the stabilisation period of $3 \mathrm{~h}$, tissues were subsequently incubated with different fatty acids. A series of preliminary tests were performed in quadruplicate, to determine the adequate fatty acid concentration $(50,150$ or $300 \mu \mathrm{M})$ and incubation time (1 or $3 \mathrm{~h}$ ) for any of the three fatty acids assayed (ARA, EPA and DHA). Best cortisol stimulation was found with fatty acid concentrations of $50 \mu \mathrm{M}$ and an incubation time of $1 \mathrm{~h}$ (Table 1) and these conditions were used afterwards in all the research experiments. Both in these preliminary tests and in the research experiments, perfusion medium was supplemented with the corresponding concentration of different fatty acids ARA, EPA, DHA and DHGLA (diluted in less than $0.5 \%$ of ethanol/medium $\mathrm{v} / \mathrm{v}$ ) prior to tissue incubation. In a second series of experiments to clarify the action mechanisms of these fatty acids, tissues were incubated with a COX inhibitor indometacin (INDO) for $20 \mathrm{~min}$ at a concentration of $25 \mu \mathrm{M}$ diluted in superfusion medium. After incubation with the fatty acids, the perfused tissues were stimulated with ACTH at a concentration of $5 \mathrm{nM} \mathrm{hACTH}_{1-39}$ (Sigma) for $20 \mathrm{~min}$. Subsequently, perfusion was maintained for another $170 \mathrm{~min}$, fraction samples being collected every $20 \mathrm{~min}$ during this period. Cortisol stimulation factor was calculated by the comparison of maximum cortisol released after ACTH stimulation with baseline cortisol released (maximum releasebaseline release)/(baseline release) (Rotllant et al. 2001). In all the series of experiments, each treatment was assayed in quadruplicate.

\section{Cortisol measurements}

Cortisol concentration in the perfused fluid was determined by RIA (Rotllant et al. 2001). The antibody used for the assay was purchased from Biolink, S.L. (Costa Mesa, CA, USA) in a

Table 1 Effect of two fatty acid concentrations (50 and $150 \mu \mathrm{M}$ ) and two incubation times ( $1 \mathrm{~h}$ and $3 \mathrm{~h}$ ) for three polyunsaturated fatty acids on cortisol secretion stimulation factor

\begin{tabular}{lrrrr} 
& \multicolumn{1}{c}{$\mathbf{1} \mathbf{h}$} & $\mathbf{3} \mathbf{h}$ \\
\cline { 2 - 2 } Treatment & & & \\
Control & $14 \cdot 71 \pm 2 \cdot 41$ & & $13 \cdot 28$ & \\
EPA & $50 \mu \mathrm{M}$ & & $29 \cdot 63 \pm 2 \cdot 59$ & $7 \cdot 79 \pm 3 \cdot 29$ \\
& $150 \mu \mathrm{M}$ & $7 \cdot 79 \pm 3 \cdot 29$ & - \\
ARA & $50 \mu \mathrm{M}$ & $22 \cdot 26+6 \cdot 29$ & $11 \cdot 75 \pm 4 \cdot 16$ \\
& $150 \mu \mathrm{M}$ & $12 \cdot 25 \pm 1 \cdot 86$ & - \\
DHA & $50 \mu \mathrm{M}$ & $35 \cdot 72 \pm 9 \cdot 28$ & $2 \cdot 60 \pm 1 \cdot 16$ \\
& $150 \mu \mathrm{M}$ & $4 \cdot 47 \pm 0 \cdot 28$ & -
\end{tabular}

www.endocrinology-journals.org 
final dilution of 1:6000. This antibody cross reactivity is $100 \%$ with cortisol, $11 \cdot 40 \%$ with 21 -desoxycorticosterone, $8 \cdot 90 \%$ with 11-desoxycortisol and $1 \cdot 60 \%$ with $17 \alpha$-hydroxyprogesterone. The radioactivity was quantified using a liquid scintillation counter. Cortisol levels are given as $\mathrm{ng} / \mathrm{g} / \mathrm{h}$.

\section{Statistical analysis}

Significance of difference $(P<0 \cdot 05)$ between dietary treatments was determined by ANOVA, followed by Duncan's multiple comparison test (Sokal \& Rolf 1995). Analyses were performed using SPSS software (SPSS for Windows 11.5; SPSS Inc., Chicago, IL, USA).

\section{Results}

The different incubation times and fatty acid concentrations assayed showed that $1 \mathrm{~h}$ of incubation time and a concentration of $50 \mu \mathrm{M}$ of fatty acid were the best conditions to obtain the highest effect of fatty acid on cortisol secretion stimulation factor (Table 1). As expected, after the stabilisation period of $3 \mathrm{~h}$, cortisol values remained at basal levels for these fish species and no significant differences were found among basal values for the different superfused tissues (Fig. 1).

The effects of supplementation with different HUFA on cortisol secretion are illustrated in Fig. 1. The production of cortisol by interrenal cells was modified when the medium was supplemented with HUFA in comparison with the control. Addition of n-3 fatty acids, DHA and EPA induced a higher and earlier cortisol response to ACTH than the control without fatty acid incubation. Addition of n-6 fatty acids did not modify the time of cortisol response in comparison to the control, but induced a higher response. Cortisol response was higher when ARA, EPA or DHA was added to fatty acid and lower when DHGLA was used. Such response expressed as stimulation factor was significantly $(P<0 \cdot 05)$ higher with EPA $(33 \cdot 71 \pm 4 \cdot 5$ basal secretion) and ARA $(28 \cdot 7 \pm 4 \cdot 47)$ incubation than control and DHGLA treatment groups (Fig. 2). With DHA incubation, no significant differences were found in the stimulation factor. By contrast, DHGLA showed the lowest $(P<0 \cdot 05)$ stimulation factor with an increase of only $8 \cdot 95 \pm 2 \cdot 17$.

Supplementation of INDO, a COX inhibitor, induced the stimulation of cortisol production by EPA and ARA observed in the former set of experiments, with cortisol absolute values not being different from those of the control (Fig. 3). However, a significantly higher $(P<0 \cdot 05)$ cortisol peak was obtained when the tissue was incubated with DHA, despite the addition of INDO (Fig. 3).

Comparison of cortisol stimulation factors when INDO was added showed a significantly higher $(P<0 \cdot 05)$ cortisol secretion in the tissue supplemented with EPA, ARA and DHA (Fig. 4). Thus, the stimulation factor of cortisol was $7 \cdot 83 \pm 3 \cdot 31$ when tissue was supplemented with EPA, $6 \cdot 97 \pm 4 \cdot 56$ with ARA, $13 \cdot 67 \pm 2 \cdot 66$ with DHA and only $1 \cdot 58 \pm 0 \cdot 45$ for control.

In addition, the comparison of cortisol stimulation factors between experiments with or without INDO showed that the addition of INDO significantly decreased ACTHstimulated cortisol secretion in all the treatment use of this COX inhibitor (Fig. 5). However, this impaired stimulation of cortisol production was lower in the DHA-supplemented group in which INDO caused a $40 \cdot 84 \%$ reduction in cortisol secretion, giving values that were significantly different $(P<0 \cdot 05)$ compared to EPA treatment where INDO caused

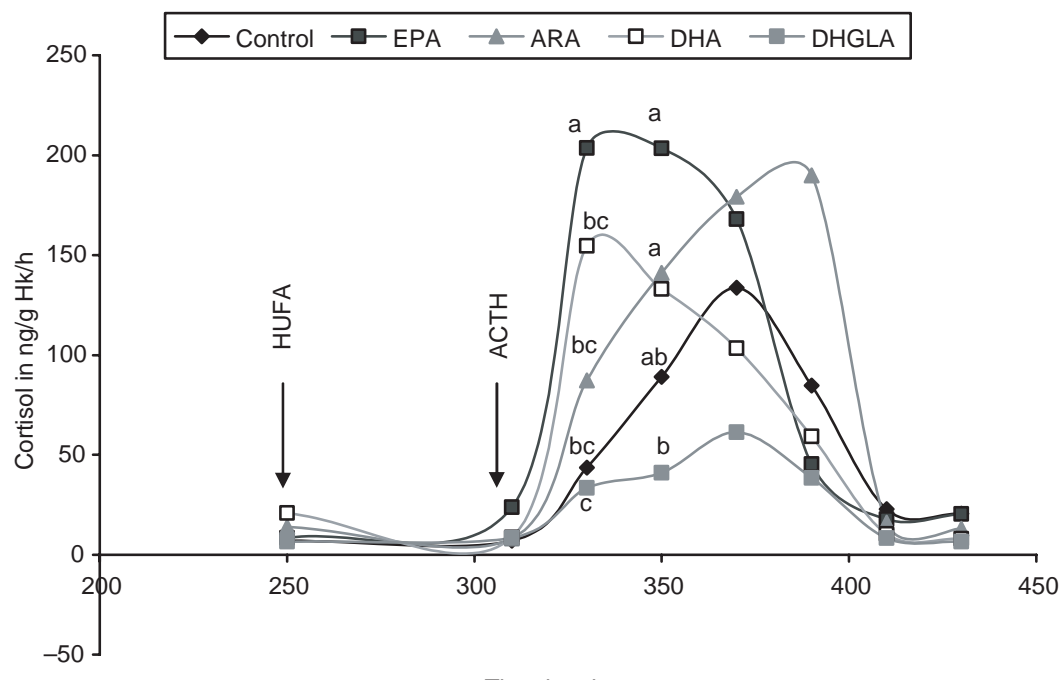

Time in min

Figure 1 Absolute cortisol secretion (ng/g Hk/h) by sea bream head kidney (Hk) after ACTH stimulation following incubation with HUFA (different letters for a given time indicate significant difference, $P<0 \cdot 05)$. 


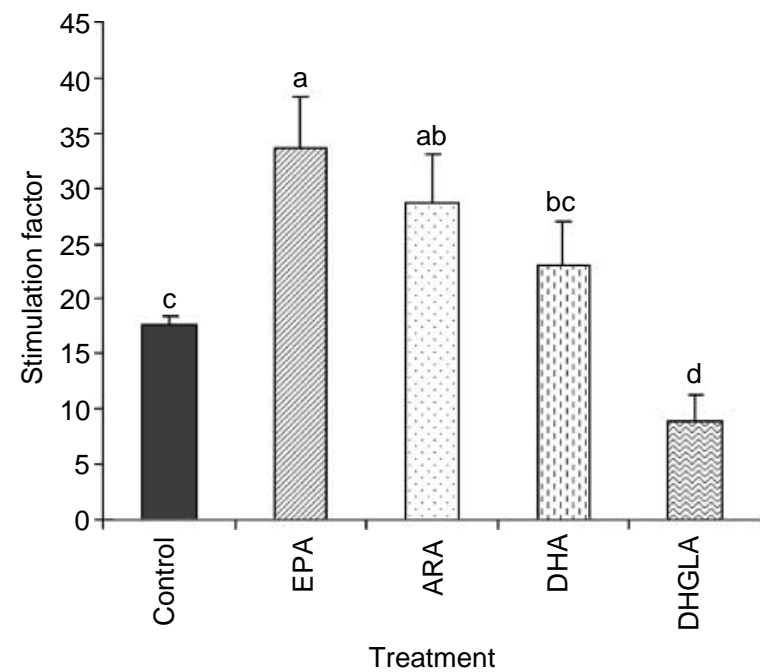

Figure 2 Cortisol stimulation factor in sea bream head kidney after ACTH stimulation following incubation with different HUFA (different letters for different treatments indicate significant difference, $P<0 \cdot 05$ ANOVA).

a $76 \cdot 76 \%$ reduction in cortisol secretion and a $75 \cdot 71 \%$ reduction with ARA treatment.

\section{Discussion}

The present study showed the first evidence of the effect of HUFA on cortisol production by ACTH-stimulated interrenal cells in fish. These results are in agreement with the observed modulating effect of dietary fatty acids in sea bream plasma cortisol levels
(Montero et al. 1998, 2001) and confirm the hypothesis of these authors about the effective action of these fatty acids on the cortisol secretion by the interrenal cells in gilthead sea bream.

Both ARA and EPA promoted ACTH-induced cortisol production in sea bream interrenal cells used in the present experiment. Dietary EPA has been shown to affect fish stress resistance in several species. Although it promoted the growth and survival of the red sea bream (Watanabe et al. 1989), gilthead sea bream (Liu et al. 2002) and Japanese flounder (Furuita et al. 1998), its effects on larval stress resistance seem to depend on species and dietary levels. For instance, elevation of dietary EPA increased red sea bream handling stress resistance (Watanabe et al. 1989) and gilthead sea bream resistance to air exposure and temperature shock, but not to salinity stress (Liu et al. 2002). On the contrary, too high EPA levels reduced stress resistance to air exposure in Japanese flounder (Furuita et al. 1998). ARA has also been shown to affect stress resistance in several fish species. Dietary ARA levels of about 1\% dry weight feed are necessary not only for optimum growth and survival of sea bream larvae (Bessonart et al. 1999), but also for improved stress resistance after handling (Koven et al. 2003, Van Anholt et al. 2004). Dietary ARA levels close to those used by these authors did not affect the handling of stress resistance in Japanese flounder, whereas higher ones reduced larval stress resistance (Furuita et al. 1998).

These differences of the effects of dietary EPA or ARA on stress resistance in different species may also be related to different ratios among these fatty acids, since both are competing substrates for cyclooxygenase enzymes (Izquierdo et al. 2001). For instance, in Atlantic salmon, alteration in the dietary ratio of n-3/n-6 fatty acids has been shown to prevent stress susceptibility to transport (Bell et al. 1991). The present

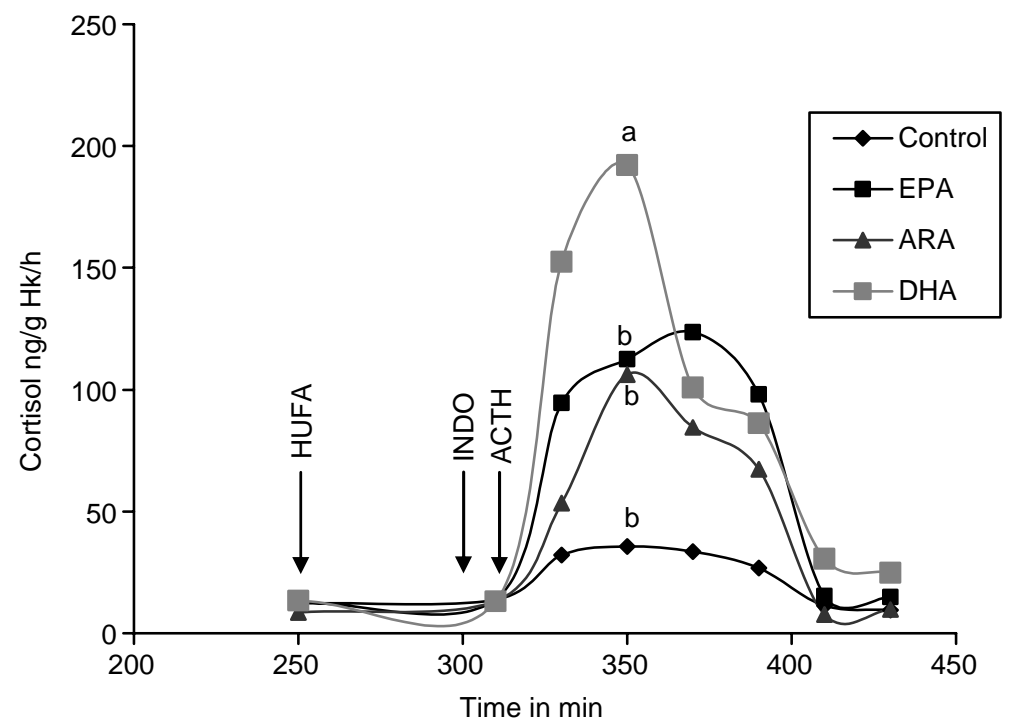

Figure 3 Absolute cortisol secretion (ng/g Hk/h) by sea bream head kidney (Hk) after ACTH stimulation following incubation with different HUFA and INDO supplementation (different letters for a given time indicate significant difference, $P<0 \cdot 05$ ). 


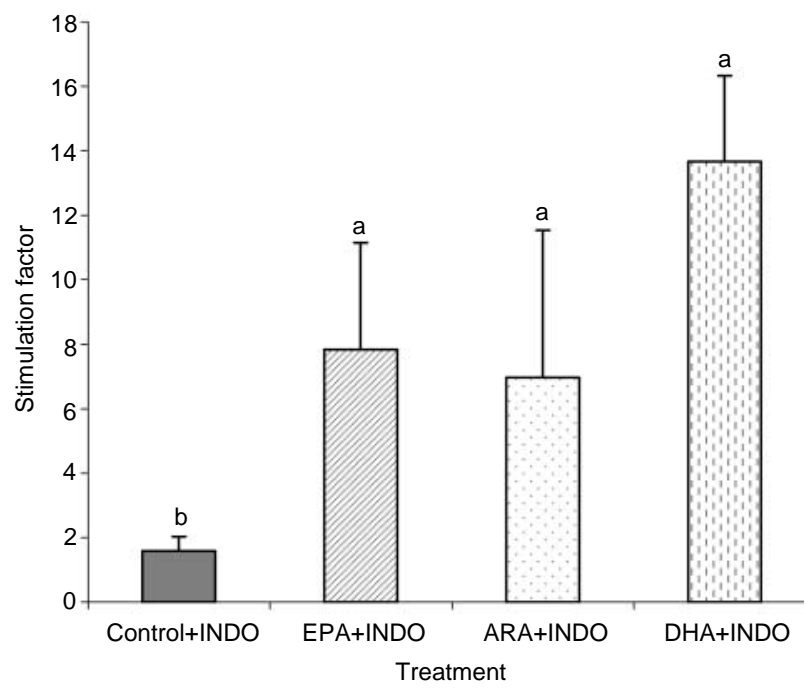

Figure 4 Cortisol stimulation factor in sea bream head kidney after ACTH stimulation following incubation with different HUFA and INDO supplementation (different letters for indicate significant differences among treatment).

study shows the first evidence found in fish that cyclooxygenase-derived metabolites are involved in ACTHinduced cortisol release by interrenal cells. The strong reduction of cortisol release caused by INDO addition in EPA and ARA supplemented groups suggested that the effect of these fatty acids was, at least partly, mediated by their cyclooxygenase-derived metabolites. Both fatty acids have been found to be good precursors of cyclooxygenase-derived PG in fish (Bell et al. 1994a, Ganga et al. 2005). In turn, cyclooxygenase-derived PG have been shown to increase in vitro cortisol release in interrenal tissue of female frogs during

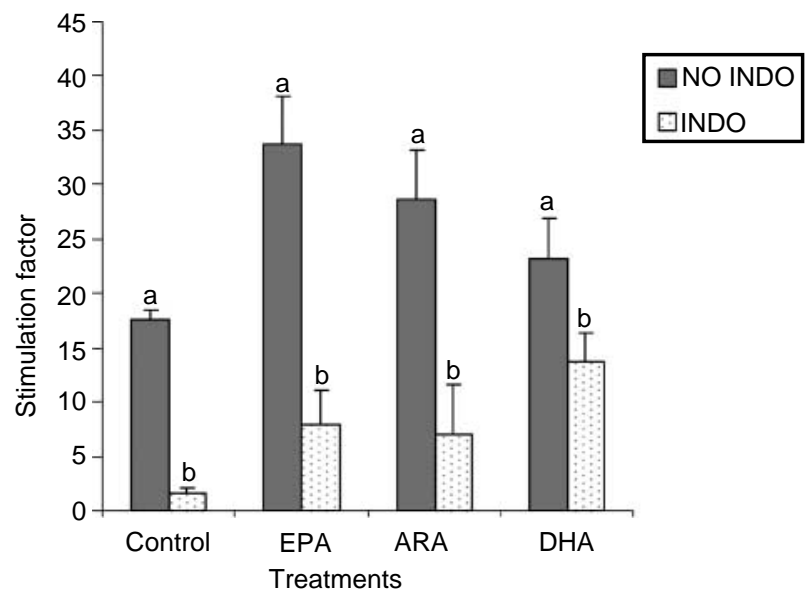

Figure 5 Comparison of cortisol stimulation factor in sea bream head kidney after ACTH stimulation following incubation with different HUFA and including (filled bars) or not (dotted bars) INDO supplementation (different letters for control or each fatty acid incubation indicates significant differences by INDO addition). ovulation (Gobbetti \& Zerani 1993) and in human adrenal cells as well (Vakharia \& Hinson 2005).

Interestingly, DHA stimulation of ACTH-induced cortisol production was lower than that caused by EPA or ARA. Besides, the inhibitory effect of INDO in the DHAsupplemented group was not so marked as in the other treatments, suggesting that the action of DHA in cortisol release from ACTH-stimulated interrenal cells is less dependent on COX metabolites in gilthead sea bream. Indeed, this fatty acid is a poorer substrate for COX than EPA or DHA. The action of DHA on interrenal cells, whether it is direct or mediated by its lipoxygenase derivatives, still has to be elucidated since lipoxygenase metabolites have been shown to modify the hormone-induced release of cortisol in mammal adrenal tissues (Wang et al. 2000, Yamazaki et al. 2001). Using nordihydroguaiaretic acid, a lipoxygenase inhibitor, cortisol secretion was inhibited in response to ACTH in bovine adrenocortical cells (Wang et al. 2000).

DHA has long been known for its high value as an essential fatty acid for marine fish (Watanabe 1982), particularly during larval stages (Izquierdo et al. 1989) when it invariably promotes growth, survival and stress resistance to a higher extent than EPA or ARA in all the studied species (Watanabe et al. 1989, Kanazawa 1997, Rodríguez et al. 1997, Furuita et al. 1999, Izquierdo et al. 2005). In gilthead sea bream, dietary deficiencies of n-3 HUFA and especially DHA have been shown to increase plasma cortisol levels after both acute (net chasing) and chronic (high stocking density) stress (Montero et al. 1998, 2001). Besides, imbalances in the dietary $n-3 / n-6$ fatty acids ratio induced by the inclusion of vegetable oils in the diet have been shown to alter the release of cortisol after stress in this species (Montero et al. 2003) and in other species such as chinook salmon (Welker \& Congleton 2003). The role of dietary oils on stress response in fish remains unclear, but results indicate that dietary fatty acids could be regulating the in vivo stress response through the mechanisms discussed above. Moreover, vegetable oils in fish diets have been shown to regulate COX-derived eicosanoids directly (Ganga et al. 2005). Dietary supplementation of other fatty acids such as ARA seems to be affecting plasma cortisol levels after stress (Van Anholt et al. 2004), although the effect on cortisol release in vivo is dose dependent, since high levels of ARA in diet seem to be detrimental to chronic stress resistance in larval gilthead sea bream (Koven et al. 2003).

Concentrations of fatty acids used in the present study were those providing the maximum cortisol stimulation factor $(50 \mu \mathrm{M})$. However, higher concentrations reduced and even inhibited cortisol secretion (Acerete L, Ganga R, Tort L \& Izquierdo MS. unpublished results), suggesting a concentration dependency in the type of effect of these fatty acids. This is the case in other organs such as testicles where medium concentrations of ARA $(3-30 \mu \mathrm{M})$ induced testosterone production in testicular cells of male sea bass, whereas high concentrations $(300 \mu \mathrm{M})$ inhibited it (Asturiano 1999). Despite the fact that no previous data has been published on in vitro exposures of fish interrenal cells to fatty acids, cytotoxic 
effects at the membrane level have been found in mammalian tissues, including renal cells (Zager et al. 1997). Particularly, excess of ARA and its derived eicosanoids has been found to cause apoptosis associated with oxidative stress in human leukocytes (Pompeia et al. 2002). Studies are being conducted at present to elucidate the effect of low and high physiological concentrations of fatty acids on ACTH-induced cortisol release by fish interrenal cells. Although this superfusion method is widely used for studies of interrenal tissue in fish (Rotllant et al. 2001), it prevents the possible control of blood flow by COX-derived prostanoids. Nevertheless, new results have shown the vasoregulatory function of COX-derived products in fish (Stensløkken et al. 2002), none of them relate though to interrenal tissues.

In summary, the role of ARA and EPA in the ACTHinduced release of cortisol from gilthead sea bream interrenal cells seems to be partly related to COX-derived metabolites dependent on ARA and EPA, whereas the role of DHA seems to be dependent on other factors. Both EPA and ARA as single supplemented fatty acids increased the ACTH-induced cortisol release from gilthead sea bream interrenal cells whereas the effect of DHA was weaker. A well-balanced supplementation of these three fatty acids could be necessary to regulate cortisol release from interrenal cells in gilthead sea bream.

\section{Acknowledgements}

The authors want to acknowledge the provision of fish by the Granja Marina del Masnou. This study was supported by grants AGL-2003-03112 (Ministry of Education) and Centre de Referencia en Aquiicultura (Generalitat Catalunya). The authors declare that there is no conflict of interest that would prejudice the impartiality of this scientific work.

\section{References}

Asturiano JF 1999 El proceso reproductivo de la lubina europea (Dicentrarchus labrax L.), Efectos de los ácidos grasos de la dieta: estudios in vivo e in vitro PhD. Thesis. Valencia University, Spain, p. 251.

Balfry SK, Maule AG \& Iwama GK 2001 Coho salmon Onchorhynchus kisutch strain differences in disease resistance and non-specific immunity, following immersion challenges with Vibrio anguillarum. Diseases of Aquatic Organisms 47 39-48.

Bell JG, McVicar AH, Park MT \& Sargent JR 1991 High dietary linoleic acid affects the fatty acid compositions of individual phospholipids from tissues of Atlantic salmon (Salmo salar): association with stress susceptibility and cardiac lesion. Journal of Nutrition 121 1163-1211.

Bell JG, Tocher DR \& Sargent JR 1994a Effect of supplementation with 20:3(n-6), 20:4(n-6) and 20:5(n-3) on the production of prostaglandins $E$ and $\mathrm{F}$ of the 1-, 2- and 3-series in turbot (Scophtalmus maximus) brain astroglial cells in primary culture. Biochimica et Biophysica Acta $1211335-342$.

Bell JG, Tocher DR, MacDonald FM \& Sargent JR $1994 b$ Effects of diets rich in linoleic (18:2n-6) and $\alpha$-linolenic acids on the growth, lipid class and fatty acid compositions and eicosanoid production in juvenile turbot (Scophtalmus maximus L.). Fish Physiology and Biochemistry 13 105-118.
Bell JG, Tocher DR, Farndale BM \& Sargent JR 1998 Growth, mortality, tissue histopathology and fatty acid composition, eicosanoid production and response to stress, in juvenile turbot fed diets rich in $\gamma$-linolenic acid in combination with eicosapentaenoic acid or docosahexaenoic acid. Prostaglandins, Leukotrienes and Essential Fatty Acids 58 353-364.

Bessonart M, Izquierdo MS, Salhi M, Hernandez-Cruz CM, Gonzalez MM \& Fernandez-Palacios H 1999 Effect of dietary arachidonic acid levels on growth and survival of gilthead sea bream (Sparus aurata L.) larvae. Aquaculture 179 265-275.

Furuita H, Takeuchi T \& Uematsu K 1998 Effects of eicosapentaenoic and docosahexaenoic acids on growth, survival and brain development of larval Japanese flounder (Paralichthys olivaceus). Aquaculture 161 59-69.

Furuita H, Kooichi K \& Takeuchi T 1999 Effect of different levels of eicosapentaenoic acid and docosahexaenoic acid in Artemia nauplii on growth, survival and salinity tolerance of larvae of the Japanese flounder, Paralycthis olivaceous. Aquaculture 170 59-69.

Ganga R, Bell JG, Montero D, Robaina L, Caballero MJ \& Izquierdo MS 2005 Effect of dietary lipids on plasma fatty acid profiles and prostaglandin and leptin production in gilthead seabream (Sparus aurata). Comparative Biochemistry and Physiology Part B: Biochemistry and Molecular Biology 142 410-418.

German B, Bruckner G \& Kinsella J 1983 Evidence against a PGF4 prostaglandin structure in trout tissue-a correction. Prostaglandins 6 207-210.

Gobbetti A \& Zerani M 1993 Prostaglandin E2 and prostaglandin F2 alpha involvement in the corticosterone and cortisol release by the female frog, Rana esculenta, during ovulation. Journal of Experimental Zoology 267 164-170.

Gupta OP, Lahlou B, Botella J \& Porthé-Nibelle J 1985 In vivo and in vitro studies on the release of cortisol from interrenal tissue in trout. I. Effects of ACTH and prostaglandins. Experimental Biology 43 201-212.

Harel M, Gavasso S, Leshin J, Gubernatis A \& Place AR 2001 The effect of tissue docosahexaenoic and arachidonic acids levels on hypersaline tolerance and leucocyte composition in striped bass (Morone saxatilis) larvae. Fish Physiology and Biochemistry 24 113-123.

Henderson RJ \& Tocher DR 1987 The lipid composition and biochemistry of freshwater fish. Progress in Lipid Research 26 281-347.

Hong S, Tjonahen E, Morgan EL, Lu Y, Serhan CN \& Rowley AF 2005 Rainbow trout (Oncorhynchus mykiss) brain cells biosynthesize novel docosahexaenoic acid-derived resolvins and protectins-mediator lipidomic analysis. Prostaglandins, other lipid mediators 78 107-116.

Hontela A 1997 Endocrine and physiological responses of fish xenobiotics: Role of glucocorticosteroid hormones. In Reviews in Toxicology. Environmental Toxicology, pp 1-46. The Netherlands: ISO Press.

Horrobin DF 1983 The regulation of prostaglandin biosynthesis by the manipulation of essential fatty acid metabolism. Revision of Pure Applied Science 4 339-383.

Izquierdo MS 1996 Essential fatty acid requirements of cultured marine fish larvae. Aquaculture Nutrition 2 183-191.

Izquierdo MS, Watanabe T, Takeuchi T, Arakawa T \& Kitajima C 1989 Requirement of larval red seabream Pagrus major for essential fatty acids (Nippon Suisan Gakkaishi). Bulletin of Japan Social Science Fish 55 859-867. Izquierdo MS, Tandler A, Salhí M \& Kolkkovski S 2001 Influence of dietary polar lipids quantity and quality on ingestion and assimilation of labelled fatty acids by larval gilthead sea bream. Aquaculture Nutrition 6 153-160.

Izquierdo MS, Montero D, Robaina L, Caballero MJ, Rosenlund G \& Ginés R 2005 Alterations in fillet fatty acid profile and flash quality in gilthead seabream (Sparus aurata) fed vegetable oils for a long term period, recovery of fatty acid profiles by fish oil feeding. Aquaculture 250 431-444.

Kanazawa A 1997 Effects of docosahexaenoic acid and phospholipids on stress tolerance of fish. Aquaculture 155 129-134.

Kocsis JF, Rinkardt NE, Satterlee DG, Weber H \& Carsia RV 1999 Concentration-dependent, biphasic effect of prostaglandins on avian coticosteroidogenesis in vitro. General and Comparative Endicronology 115 132-142.

Koven WM, Van Anholt RD, Lutzky S, Ben Atia I, Nixon O, Ron B \& Tandler A 2003 The effect of dietary arachidonic acid on growth, survival, 
and cortisol levels in different-age gilthead seabream larvae (Sparus auratus) exposed to handling or daily salinity change. Aquaculture 228 307-320.

Lands WEM 1989 Differences in n-3 and n-6 eicosanaid precursors. In Advances in Prostaglandin Thromboxane and Leukotriene Research, Vol 9, pp 602-605. Eds B Samuelsson \& PYK Wong. New York, NY, USA: Raven Press.

Liu J, Caballero MJ, El-Sayed Ali T, Izquierdo MS, Hernández Cruz CM, Valencia A \& Fernández-Palacios H 2002 Necessity of dietary lecithin and eicosapentaenoic acid for growth, survival, stress resistance and lipoprotein formation in gilthead sea bream (Sparus aurata). Fish Science 68 1165-1172.

Matsumoto H, Iijima N \& Kayama M 1989 The prostaglandin synthesis in marine fish thrombocytes. Comparative Biochemistry and Physiology 93B 397-402.

Montero D, Tort L, Izquierdo MS, Robaina L \& Vergara JM 1998 Depletion of serum alternative complement pathway activity in gilthead seabream caused by alpha-tocopherol and n-3 HUFA dietary deficiencies. Fish Physiology and Biochemistry 18 399-407.

Montero D, Tort L, Robaina L, Vergara JM \& Izquierdo MS 2001 Low vitamin $\mathrm{E}$ in diet reduces stress resistance of gilthead seabream (Sparus aurata) juveniles. Fish and Shellfish Immunology 11 473-490.

Montero D, Kalinowski T, Obach A, Robaina L, Tort L, Caballero MJ \& Izquierdo MS 2003 Vegetable lipid sources for gilthead seabream (Sparus aurata): effects on fish health. Aquaculture 225 353-370.

Mustafa T \& Srivastava KC 1989 Prostaglandins (eicosanoids) and their role in ectothermic organisms. Advance Comparative Environmental Physiology $\mathbf{5}$ 157-207.

Nablone G, Grynberg A, Chevalier A, Leonardi J, Termine E \& Lafont H 1990 Phospholipase A activity of cultures rat ventricular myocytes is affected by the nature of cellular polyunsaturated fatty acids. Lipids 25 301-306.

Pompeia C, Freitas JJS, Kim JS, Zyngier SB \& Curi R 2002 Arachidonic acid cytotoxicity in leukocytes: implications of oxidative stress and eicosanoids synthesis. Biology of Cells 94 251-265.

Rodríguez C, Perez JA, Diaz M, Izquierdo MS, Fernandez-Palacios H \& Lorenzo A 1997 Influence of the EPA/DHA ratio in rotifers on gilhead seabream (Sparus aurata) larval development. Aquaculture 150 77-89.

Rotllant J \& Tort L 1997 Cortisol and glucose responses after acute stress by net handling in the sparid red porgy previously subjected to crowding stress. Journal of Fish Biology 51 21-28.

Rotllant J, Balm PHM, Ruane NM, Pérez-Sánchez J, Wendelaar Bonga SE \& Tort L 2000a Pituitary proopiomelanocortin-derived peptides and hypothalamic-pituitary-interrenal axis activity in gilthead sea bream (Sparus aurata) during prolonged crowding stress: differential regulation of adrenocorticotropin hormone and melanocyte-stimulating hormone release by corticotrophin-releasing hormone and thyrotropin-releasing hormone. General and Comparative Endocrinology 119 152-163.

Rotllant J, Balm PHM, Wendelaar Bonga SE, Pérez-Sánchez J \& Tort L 2000 b A drop in ambient temperature results in a transient reduction of interrenal ACTH responsiveness in the gilthead sea bream (Sparus aurata L.). Fish Physiology and Biochemistry 23 265-273.

Rotllant J, Balm PHM, Pérez-Sánchez J, Wendelaar Bonga SE \& Tort L 2001 Pituitary and interrenal function in gilthead sea bream (Sparus aurata L., Teleosteí) after handling and confinement stress. General and Comparative Endocrinology 121 333-342.

Sokal RR \& Rolf SJ 1995 Biometry. In The Principles and Practice of Statistics in Biological Research. 3rd edn, p 419. New York, NY, USA: WH Freeman and Company.
Stensløkken KO, Sundin L \& Nilsson GE 2002 Cardiovascular effects of prostaglandin $\mathrm{F}_{2 \alpha}$ and prostaglandin $\mathrm{E}_{2}$ in Atlantic cod (Gadus morhua). Journal of Comparative Physiology B Biochemical, Systemic, and Environmental Physiology 172 363-369.

Thompson I, White A, Fletcher TC, Houlihan DF \& Secombes CJ 1993 The effect of stress on the immune system of Atlantic salmon (Salmo salar L.) fed diets containing different amounts of vitamin C. Aquaculture $1141-18$.

Tocher DR 1995 Glycerophospholipid metabolism. In Biochemistry and Molecular Biology of Fishes, vol. 4, Metabolic and Adaptational Biochemistry, pp 119-1957. Eds W Hochachka \& TP Mommsen. Amsterdam: Elsevier Press.

Tocher DR \& Sargent JR 1987 The effects of calcium ionophore A23187 on the metabolism of arachidonic and eicosapentaenoic acids in neutrophils a marine teleost fish rich in (n-3) polyunsaturated fatty acids. Comparative Biochemistry and Physiology 87B 733-739.

Uhing RJ, Cowlen MS \& Adams DO 1990 Mechanisms regulating the production of arachidonate metabolites in mononuclear phagocytes. Current Topics in Membranes Transport 35 349-374.

Vakharia K \& Hinson JP 2005 Lipopolysaccharide directly stimulates cortisol secretion by human adrenal cells by a cyclooxygenase-dependent mechanism. Endocrinology 146 1398-1402.

Van Anholt RD, Spanings FAT, Koven WM \& Wendelaar Bonga SE 2004 Dietary supplementation with arachidonic acid in tilapia (Oreochromisi mossambicus) reveals physiological effects not mediated by prostaglandins. General and Comparative Endocrinology 139 215-226.

Wang H, Walker SW, Mason JI, Morley SD \& Williams BC 2000 Role of arachidonic acid metabolism in ACTH-stimulated cortisol secretion by bovine adrenocortical cells. Endocrine Research 26 705-709.

Watanabe T 1982 Lipid nutrition in fish. Comparative Biochemistry and Physiology 73B 3-15.

Watanabe T, Izquierdo MS, Takeuchi T, Satoh S \& Kitajima C 1989 Comparison between eicosapentaenoic and docosahexaenoic acids in terms of essential fatty acid efficacy in larval red seabream (Nippon Suisan Gakkaishi). Bulletin Japan Social Science Fish 55 1635-1640.

Wendelaar Bonga SE 1997 The stress response in fish. Physiology Review $\mathbf{7 7}$ 591-625.

Welker TL \& Congleton JL 2003 Relationship between dietary lipid source, oxidative stress, and physiological response to stress in sub-yearling Chinook salmon (Oncorhynchus tshawytsha). Fish Physiology and Biochemistry $29225-235$.

Yamazaki T, Higuchi K, Kominami S \& Takemori S 2001 15-Lipoxygenase metabolite(s) of arachidonic acid mediates adrenocotropin action in bovine adrenal steroidogenesis. Endocrinology 137 2670-2675.

Yin Z, Lam TJ \& Sin YM 1995 The effects of crowding stress on the nonspecific immune response in fancy carp (Cyprinus carpio L.). Fish and Shellfish Immunology 5 519-529.

Zager RA, Iwata M, Conrad DS, Burkhart KM \& Igarashi Y 1997 Altered ceramide and sphingosine expression during the induction phase ischemic acute renal failure. Kidney International 52 60-70.

\author{
Received in final form 23 March 2006 \\ Accepted 29 March 2006 \\ Made available online as an Accepted Preprint \\ 21 April 2006
}

